\title{
Carboline's systems approach to the maintenance of coating systems for steel structures in the oil and gas industry
}

\author{
Gennadiy Konovalov ${ }^{1, *}$ \\ ${ }^{1}$ Carboline Benelux, Zilverenberg 18, 5234 GM 's-Hertogenbosch, The Netherlands. www.carboline.com
}

\begin{abstract}
The article discusses options for optimal repair systems with several advantages compared with competitive solutions in the market of protective coatings. The proposed materials have a high tolerance to the degree of surface preparation, compatibility with old protective systems, as well as low levels of internal stresses arising in the repair layer of coating, which significantly reduces the risk of pulling off the old protective coatings after repair.
\end{abstract}

\section{The Economics of Overcoating}

When overcoating aged paint, you will not receive the same level of performance offered by a properly selected high performance coating system applied to blast cleaned steel. Furthermore, overcoating cannot proceed indefinitely due to its continued increase in overall coating thickness and an increasingly shorter maintenance cycle. Eventually paint removal or structure obsolescence occurs.

Specifiers must develop a long-range plan to economically approach their painting. Cosmetics now must play a lesser role in the decision of what to paint. Previously, engineers would prioritize structures in the worse condition for painting. These would often require blast removal while items which qualify for overcoating are postponed until they too require blasting. A protective coating must be considered as an asset which depreciates and requires maintenance just like a car.

An economically oriented maintenance plan balances an overcoating program with a removal and repaint program to optimize cost per year of service. It may even include the ultimate sacrifice, let structural integrity erode to corrosion.

The difficulty is in determining the economic soundness of any maintenance strategy. Old coating removal costs vary widely depending on the contract wording, location, environmental sensitivity and many other factors. Service life estimates are just that, rough estimates and are more difficult to predict when the substrate is aged paint in varying condition. Still, there are some fundamental elements necessary in an overcoating maintenance strategy:

- Good performance should be achieved with your overcoat system (corrosion protection).

- Future overcoating is likely plausible (system stress does not grow).

- Delamination failure incidence is held to an absolute minimum (structures are properly qualified for overcoating).

Many products will adhere to old coatings. Many of these will also adhere to hand tool cleaned steel. These two characteristics are necessary in an overcoat product but do not guarantee its suitability for overcoating.

Rustbond Penetrating Sealer provides these features and a whole lot more. It was formulated to be a component of overcoat systems that increase long term performance, increase the likelihood that overcoating will be possible in the future and that delamination is avoided

Figure 1 shows the relative cost of removal versus overcoating. This chart compares a $\$ 2$ per square foot overcoating to a $\$ 10$ per square foot removal

\footnotetext{
* G. Konovalov: gkonovalov@,carboline.com
} 


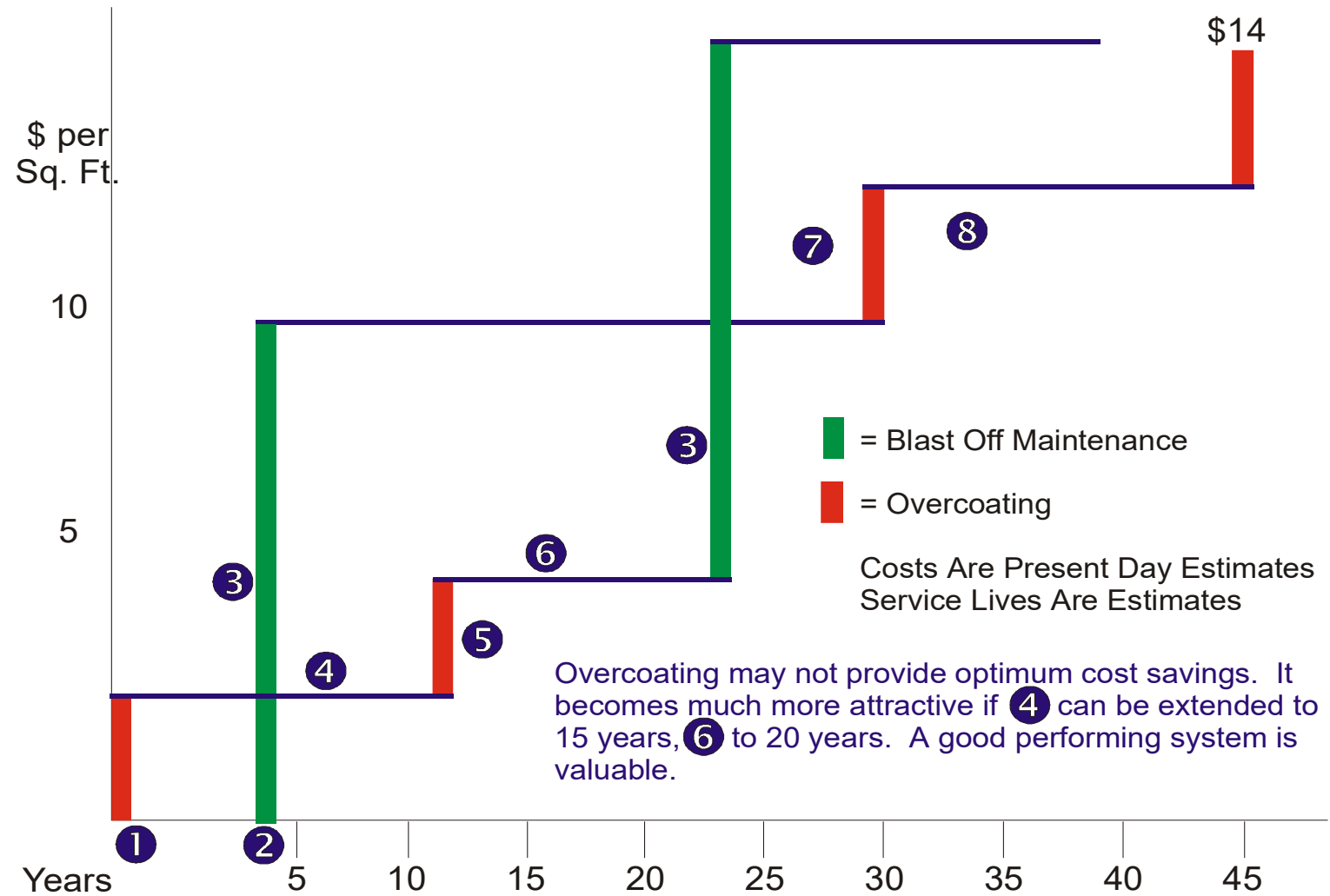

(1) Overcoat, i.e., SP-2, spot prime, full topcoat at $\$ 2$ per square foot with appropriate system.

2 If removal is necessary, same structure selected for option 1 can have painting delayed (i.e., 4 years).

3 Blast remove, i.e., SP-6, epoxy zinc rich / epoxy / urethane @ \$10 per square foot.

4 Overcoat system requiring maintenance in ten years.

5 Overcoating is more economical if it can be done twice or structure becomes obsolete before blasting is required.

6 Third overcoating is stretching your luck. Figure on blasting after overcoating window is expired $\sim 14$ years.

(7) Spot prime of zinc rich system with epoxy mastic and full color coat.

8 Blast removal should never be necessary because mill scale has been removed, zinc protects against undercutting and long term adhesion between coats will be maintained. Full color coat will be desired at the time of spot painting.

Fig. 1. Relative cost of removal versus overcoating. This chart compares a $\$ 2$ per square foot overcoating to a $\$ 10$ per square foot removal.

\section{Overcoating Strategies}

People responsible for a large inventory of lead coated structures may be forced to make sacrifices in their painting program. Some of the decisions being made daily as economic necessity are listed:

- Do nothing - let the structure go because:
It is not overcoatable, and blasting is too expensive.

$\checkmark$ It will be obsolete before it loses too much metal, and we don't care what it looks like.

$\checkmark$ We can replace it at a reasonable cost relative to repainting.

$\checkmark$ We don't have the money.

$\checkmark$ Slow corrosion rate.

- Do "zone painting" - protect only areas that need attention or provide repainting only on the most 
demanding spots with overcoating on the balance of the structure because:

$\checkmark$ Only the corrosive sections need attention.

$\checkmark$ We can only afford partial protection.

$\checkmark$ The structure is not overcoatable, but needs more protection.

$\checkmark$ This is the only way to maintain structural integrity with our budget.

- Complete overcoat some structures, full repaint others because:

$\checkmark$ Overcoating is more justified in environmentally sensitive locations.

$\checkmark$ Balancing a repaint and overcoat scheme solves corrosion problems and makes progress towards eliminating the lead.

$\checkmark$ Some coatings are too far gone to overcoat.

$\checkmark$ This flexible plan accomplishes necessary work with a limited budget.

- Overcoat some structures, do nothing on others:

$\checkmark$ We simply cannot afford total removal.

$\checkmark$ Corrosion rate is low on those items left unmaintained.

$\checkmark$ Our overcoat system is a long-term performer.

This flexible plan provides for the implementation of the necessary work package for a limited budget.

Our overcoating systems are more durable and efficient and allow the customer to develop a specific plan that meets budget requirements for maintaining protective systems in optimal functional condition.

\section{Characteristics of Successful Overcoating Materials}

Ideally, we would like to have a low stress, low risk, inexpensive and long-lasting overcoat system to make overcoating economical and as risk-free as possible. Long service life in coatings normally requires good barrier properties. To improve impermeability, formulators increase the crosslink density (or polymerization) and film build of the material. This adds stress. The chemist's challenge is to balance these properties while providing good wetting and rust penetration.

Carboline manufactures many coatings for overcoat application. Descriptions of three dominant brands, Carbomastic, Carbocoat and Rustbond follow

\subsection{Important Overcoating Features Found in Carbomastic 15}

- $\quad$ Low Solvent Content

$\checkmark$ Does not soften and weaken old coatings.

$\checkmark$ Very low shrinkage during cure, low stress imparted to poorly adhered coatings.

- $\quad$ Thixotropic

$\checkmark$ Outstanding edge coverage over edges of old coatings and steel corners. $\checkmark$ High film build provides excellent one coat protection.

$\checkmark$ "Buries" steel profiles left rough by corrosion.

- $\quad$ Outstanding Wetting Properties

$\checkmark$ Penetrates corrosion products and crevices.

$\checkmark$ Provides intimate adhesion to smooth surfaces, i.e., mill scale, old slick coating surfaces

$\checkmark$ Very forgiving of surface contaminants.

$\checkmark$ Reduces undercutting corrosion even when applied over rusty steel.

- $\quad$ Slow Curing

$\checkmark$ Slow curing mechanism enables Carbomastic 15 to fully wet out and absorb onto minimally prepared surfaces regardless of temperature and humidity conditions during application.

- $\quad$ Very, Very Low Moisture Permeability

$\checkmark$ Cross linked epoxy provides dense barrier to moisture and chemicals.

- $\quad$ Low Stress Liquid Epoxy Resins

$\checkmark$ Very, very low stress is developed during curing and in extended service.

$\checkmark$ Does not embrittle after decades of service.

- $\quad$ Aluminum Flakes

$\checkmark$ Provide barrier to moisture penetration.

$\checkmark$ Reflect UV and protect epoxy for long term protection.

- Inexpensive

$\checkmark$ For overcoating to be justified it must be more economical than blast removal.

- $\quad$ Passed Important Test of Time

$\checkmark$ Hundreds of thousands of gallons used in overcoating are still in service.

\subsection{Rustbond Penetrating Sealer Mechanisms of Protection}

Rustbond Penetrating Sealer was formulated specifically for the purpose of overcoating old marginally adhered coatings. Carboline called on its vast experience in overcoat product formulation to create Rustbond. The resulting product is not a paint. Rustbond Penetrating Sealer takes the characteristics of good overcoat paint products to their ultimate level to enhance the success rate of overcoating and improve overcoat system performance without adding prohibitive expense.

The listed in Table 1 characteristics of Rustbond Penetrating Sealer all enhance the products' functionability in an overcoat paint system.

Rustbond starts with the Carbomastic concept but takes the wetting and penetration properties to an extreme by sacrificing film build. This gives Rustbond unique protective mechanisms like using it as a full primer before spot primer application. A new way to protect with minimal risk.

Rustbond Adhesion vs. Carbomastic are given in table 2. Steel was weathered outside and contained 3-5 mils of red rust. 
Table 1. Characteristics of Rustbond Penetrating Sealer

\begin{tabular}{|l|l|}
\hline \multicolumn{1}{|c|}{ Characteristics } & \multicolumn{1}{c|}{ Purpose } \\
\hline Capillary Action & $\begin{array}{l}\text { Rustbond Penetrating Sealer draws into crevices and under edges of } \\
\text { loose coatings. Reduces crevice corrosion on back to back angles, rivets, } \\
\text { etc. }\end{array}$ \\
\hline Outstanding Wetting & $\begin{array}{l}\text { Soaks deeply into rust and provides intimate adhesion to smooth surfaces } \\
\text { such as mill scale and galvanized steel. }\end{array}$ \\
\hline Contains Corrosion Inhibitors & Reduces undercutting corrosion and sub film corrosion. \\
\hline Fully Topcoatable & $\begin{array}{l}\text { Compatible with virtually all generic types. Provides optimum overcoat } \\
\text { system customizing. }\end{array}$ \\
\hline Solvent Resistant & Isolates solvent sensitive coatings from solvent bearing topcoats. \\
\hline Low Stress & Curing and aging places little stress on existing coatings. \\
\hline Flexible & Insulates topcoat stresses from old coatings. \\
\hline Metered Film Build & Prevent tendency to apply heavy coats. \\
\hline
\end{tabular}

Table 2. Rustbond Adhesion vs. Carbomastic

\begin{tabular}{|c|c|c|c|c|}
\hline Substrate & Primer & Topcoat & Adhesion in PSI & Comments \\
\hline \multirow{2}{*}{ Rusty Steel } & Rustbond & & 1525 & $100 \mathrm{~S}$ \\
\cline { 2 - 5 } & CM 15 & & 914 & $100 \mathrm{PC}$ \\
\hline \multirow{2}{*}{ Intact Mill Scale } & Rustbond & & 2013 & $100 \mathrm{~S}$ \\
\cline { 2 - 5 } & CM 15 & & 1131 & $100 \mathrm{PC}$ \\
\hline \multirow{2}{*}{ S.B. Steel } & Rustbond & & 1500 & $100 \mathrm{PC}$ \\
\cline { 2 - 5 } & CM 15 & & 1025 & $50 \mathrm{~S} / 50 \mathrm{TC}$ \\
\hline Rusty Steel & Rustbond & D3359 & 1596 & $90 \mathrm{~S} / 10 \mathrm{TC}$ \\
\hline Rusty Steel & Rustbond & $133 \mathrm{HB}$ & 1494 & $100 \mathrm{TC}$ \\
\hline Rusty Steel & Rustbond & CM 15 & 914 & $100 \mathrm{~S}$ \\
\hline Rusty Steel & Rustbond & CM 90 & 1117 & $100 \mathrm{~S}$ \\
\hline Rusty Steel & Rustbond & 890 & 1179 & \\
\hline
\end{tabular}

Legend for Comments Column

$\mathrm{S}=$ Failure occurring at the substrate

$\mathrm{R}=$ Failure occurring in the rust

$\mathrm{PC}=$ Failure within the primer

$\mathrm{G}=$ Failure occurring within the glue or glue to topcoat

* Adhesion determined by Paddi Adhesion Tester

\section{Conclusions}

For cases where it is economically feasible to use partial repair of coatings, Carboline repair systems have a number of advantages compared to competitors, namely: increased penetrating power required for sealing and coating poorly prepared and hard-to-reach surface areas, low internal stresses that reduce the risk of pulling off old coatings. 